\title{
EN TORNO A LA ARQUITECTURA DOMÉSTICA SEVILLANA DEL SIGLO XIX: EL PASO DEL NEOCLASICISMO A LA ARQUITECTURA ISABELINA
}

\author{
AROUND THE DOMESTIC \\ ARCHITECTURE SEVILLANA XIX \\ CENTURY: FROM NEOCLASSICISM TO \\ ARCHITECTURE ISABELINA
}

\author{
José Manuel SuÁrez Garmendia \\ Universidad de Sevilla, España \\ sgarmendia@us.es
}

La arquitectura doméstica sevillana inicia el siglo XIX manteniendo muchos de los elementos propios del anterior aunque poco a poco va evolucionando hacia otros más clásicos, menos ornamentados, menos barrocos generando un aspecto más severo con la utilización de frontones rectos y pilastras lisas. A partir de 1825, los arquitectos procedentes de la Real Academia de San Fernando imponen un tipo de fachada neoclásica al modo villanovino. En la segunda mitad del siglo se dio un tipo de palacio de clara raigambre francesa cuyo mejor exponente es la Casa de las Sirenas. Además de las construcciones destinadas a las clases pudientes surge un tipo de viviendas para el proletariado en las que se primaron la optimización del espacio y, a veces, los aspectos higiénicos.

Palabras clave: Alonso Moreno, Casa de Andueza, Casa de las Sirenas, Corral de los Chícharos, Eduardo García Pérez.

Seville's domestic architecture began the 19th century preserving most of own components of previous century however changing to others that could be considered more classical, less embroidered and less baroque, developing serious appearance due to straight pediments and flat pilasters utilization. From 1825, a kind of neoclassical facade (villanovino style) is imposed by architects coming from "Real Academia de San Fernando". In the second half of the century a kind of french-style palace can be founded and "Casa de las Sirenas" is best model. Besides wealthier classes constructions, a new kind of houses for proletariat is going to be appeared where space's optimization and sometimes healthy conditions have been prioritized.

Keywords: Alonso Moreno, Casa de Andueza, Casa de las Sirenas, Corral de los Chícharos, Eduardo García Pérez 
En Sevilla el paso del siglo XVIII al XIX se produce sin cambios bruscos en lo que a la evolución de la arquitectura doméstica se refiere. Comparando las últimas construcciones del XVIII como la nueva portada del Hospital Real, la casa de la calle Conde Ibarra 18 de 1770, la casa de las Columnas de la calle Pureza de 1780 , la mal llamada casa de los Duques del Infantado de $1780, \ldots$ todas ellas con un carácter barroco todavía, con otras arquitecturas que están ya dentro del siglo XIX como la casa del Marqués del Real Tesoro o la de Andueza...vemos que determinados elementos del diseño del siglo ilustrado van desapareciendo y van tomando formas más de acuerdo con las normas clasicistas, al menos hasta bien entrado el reinado de Isabel II.

La regularidad, la simetría, el orden, la proporción, etc. van a ser los argumentos principales que exhiban aquellos maestros que hacen las veces de arquitecto del municipio o maestro alarife para informar en contra o para hacer ver al que solicita expediente de obra nueva, que su proyecto debe corregirlo en aquellos aspectos que se le indican.

La proporción de los huecos, la eliminación de los tejados a dos aguas de las crujías de fachada, la sustitución de este cuerpo por terrazas, el derribo de secaderos y tirasoles, la organización en ejes de los huecos verticales de fachada, la eliminación de rejas cerradas para evitar el atrapamiento de las personas, los vuelos de los balcones y de rejas, sobre todo las del piso bajo para no molestar a los viandantes... constituye una amplia casuística que determina y dirige la iniciativa de los maestros de obra a la hora de enfrentarse al diseño de un edificio o a un nuevo encargo como puede ser una transformación o reparación profunda, estas últimas las más frecuentes. El análisis de las opiniones de los maestros alarifes para nosotros es del mayor interés porque éste echa mano de su elenco particular de conocimientos y poco a poco se va creando una especie de corpus al que el resto de los maestros de obra se van ciñendo en sus proyectos para no verlos rechazados.

Generalmente todas esta normas ordenancistas parten de la Real Academia de San Fernando pero solo las de carácter general, otras las aplican arquitectos académicos que forman parten de las comisiones de este organismo que, a través de su prestigio, crea un grupo de discípulos que difunde sus ideas por todo el reino. Fue el caso de Villanueva y sus discípulos, de Ventura Rodríguez, Manuel Martín Rodríguez, los Cuervo...

En Sevilla estas cuestiones se organizan según lo previsto en las normas gremiales. Anualmente se reunían el segundo día de Pascua de Resurrección en la capilla de San Andrés todos los maestro de obras habilitados y aquí se nombraba el alarife o Maestro Mayor en quién recaía la responsabilidad e hacer cumplir las ordenanzas. Así mismo se nombraban los maestros veedores y examinadores que se encargaban de hacer las pruebas necesarias y exámenes de limpio, tosco y cañero a los oficiales aspirantes al título de maestro de obras. A estos exámenes para darles la mayor rigurosidad, asistían en calidad de miembros del tribunal un Señor 
Veinticuatro y un Caballero Jurado en representación del municipio y todo ello era reflejado en el acta del examen por un Escribano Mayor del cabildo ${ }^{1}$. De igual forma se observa que estas maneras admitidas por los llamados Alarifes o Maestros Mayores se van consolidando y, al cabo de los años, si no son de uso obligatorio sí dejan muy poco margen en el diseño y en los aspectos generales de las edificaciones. Se da la circunstancia también que el ejercicio de este cargo, ahora regulado por el municipio, cambió de mano muy pocas veces a lo largo del primer cuarto del siglo y posteriormente, en la época de Arjona, con Melchor Cano, tampoco pues él se mantuvo en el nombramiento de Arquitecto Municipal desde 1826 hasta que presentó su dimisión en 1840 .

Esta situación va a durar aproximadamente desde 1767 hasta 1801 año en el que se suspenden definitivamente estos exámenes. Ahora serán los diferentes cabildos y corporaciones los que por su cuenta nombran a sus maestros cuando los precisen, al no disponer desde esta última fecha de nuevos oficiales nombrados por las normas gremiales. El más interesado por regularizar esta situación es el propio municipio para resolver la legalidad y las cuestiones técnicas que presentaban las licencias de obras reguladas por diversas Reales Órdenes. Será a partir de 1825, ya durante la asistencia de Arjona, cuando se hará cargo de emitir estos dictámenes un académico de la Real Academia de San Fernando, el arquitecto Melchor Cano acabando con un periodo de inestabilidad y también de sequía de ideas. Bien es verdad que fueron varios los motivos que se unieron para hacer evidentes esa falta de ideas sobre todo cuando la responsabilidad recaía sobre un colectivo, el gremio de albañiles, poco preparado y con pocos recursos para optar a unas enseñanzas que los cualificara. En Sevilla no había referentes, solo aquella arquitectura del glorioso pasado de la ciudad. Nuestra Academia de Bellas Artes no estaba autorizada para impartir las enseñanzas apropiadas pues solo las de Madrid, Valencia y Zaragoza desde 1817 estaban habilitadas para esta función por Real Orden de Fernando VII.

Desde el inicio del siglo muy pocas obras de nueva planta se habían realizado. Generalmente la actividad edilicia giraba en torno a las obras de consolidación, restauración, ampliación y transformación, algunas veces bastante profundas, de edificios del siglo anterior para ampliar su capacidad. Durante la ocupación francesa aquellas reformas fueron propiciadas por los mandos del ejército francés para su acomodo.

Quizás lo más interesante de la primera mitad del siglo XIX en cuanto a arquitectura doméstica pueda ser la labor del maestro agremiado Alonso Moreno la cual tenemos bien documentada y nos vas a servir para constatar lo que se hacía en estos años. La primera obra que encontramos de este maestro es del año

${ }^{1}$ SUÁREZ GARMENDIA, José Manuel: Arquitectura y urbanismo en la Sevilla del siglo XIX, Sevilla, 1986, pp. 69-76. 
$1806^{2}$ para el Marqués del Real Tesoro (calle Trajano) ${ }^{3}$. Ésta parece ser la primera de un tipo luego desarrollado por el maestro Alonso en otras casas también de la burguesía acaudalada, como la de Andueza (Figura 1).

El rango del propietario desde el punto de vista social venía representado en un código perfectamente inteligible por el resto de los ciudadanos. Aparte de otros signos parlantes como son el emplazamiento y el volumen de la construcción, se inclina para este palacete urbano por un lenguaje de elementos ornamentales neoclásicos expuestos con grandeza en una portada de dos cuerpos correspondientes a los dos pisos más el frontón recto que, por encima de la cornisa del edificio, se apoya en el antepecho de la terraza. Esta portada está muy definida por las pilastras de orden jónico y corintio con basas áticas que, en otras ocasiones serán columnas como en la casa de Andueza, lo cual acentuará su plasticidad. La fachada en su conjunto es frecuente en la ciudad, sobre todo en casas del último cuarto del siglo XVIII, aunque poco a poco se va evolucionando hacia elementos más clásicos, menos ornamentados, menos barrocos en definitiva, dando un aspecto más severo con la utilización de frontones rectos y pilastras lisas. En el interior, después de atravesar un amplio zaguán hay un patio descubierto, supuestamente con función de apeadero, desde cuya esquina se accede por la izquierda a una escalera de dos tiros. Actualmente existe una cancela más dos ladillos y su montante sobrepuesto en una labor de obra que no es de la época y que a nuestro parecer es una solución con poco sentido pero está situada justamente donde en su día estaba el portón. A través de esta cancela pasa hasta el fondo el eje teórico sobre el que se organiza el edificio con la secuencia de zaguán, cancela o portón, desembarco de la escalera a la izquierda y galería del patio, este último a la derecha. Pues bien, aquí la vista no se tropieza con nada, el patio queda desplazado a la derecha y fuera de la visual manteniendo el sentido íntimo del sector principal de la casa. Este patio es más o menos cuadrado de tres galerías y de dos plantas, la superior cerrada por ventanas adinteladas con antepechos de hierro y las galerías de debajo de columnas de mármol blanco de orden toscano con cimacios sobre los que apean arcos de medio punto. Es un esquema repetido por Alonso Moreno en varias ocasiones que se ajusta a lo que se hacía para este tipo de viviendas unifamiliares en la ciudad.

${ }^{2}$ Archivo Municipal de Sevilla (A.M.S.), Secc. 6a T. 56. Proyecto fechado el 21 de mayo de 1806 para el Marqués del Real Tesoro, situado en la calle Puerco a la entrada de ella frente a la iglesia de San Miguel (Calle Trajano, edificio de la Cámara Oficial Agrícola).

${ }^{3}$ José Manuel de Villena, hacendado en Cuba y Teniente General de la Armada, era miembro de la vieja aristocracia del siglo XVIII ligada a la producción de azúcar... que regresa en 1798 (FLORENCIO PUNTAS, Antonio: "Patrimonios indianos en Sevilla en el siglo XIX. Entre la tradición y la Innovación" en Fortuna y Negocios: Formación y Gestión de los Grandes Patrimonios (Siglos XVI-XX), Valladolid, 2002, pp. 191-215). 
La siguiente casa, encargada en 1816, fue para José Sologuren ${ }^{4}$ desaparecida no hace muchos años. Aparte de por una fotografía existente en la Fototeca de la Universidad de Sevilla ${ }^{5}$ (Figura 2), también la conocemos por el dibujo adosado al expediente de solicitud de obra nueva. Es una casa con dos alturas separadas por imposta y cornisa, coronada por un antepecho corrido de obra. La portada, centrada con los huecos principales, consta de un podio de donde arrancan dos pilastras de fustes cajeados de orden toscano que sostienen un entablamento de triglifos y metopas donde descansa el balconaje del principal, cuyo hueco también está flanqueado por otras pilastras de orden jónico que soportan un entablamento y un frontón triangular recto. En el interior hay un patio pequeño de columnas soportando arcos de medio punto. Las molduras están recorridas por líneas de dentículos al igual que en todas sus obras.

La obra más importante de Alonso Moreno y la más relevante construcción de este tipo durante el primer tercio del siglo XIX es la que le encargó Vicente Torres de Andueza ${ }^{6}$ en la calle Armas (Alfonso XII) de la que Álvarez Benavides, atribuyéndolo al citado maestro, dice que es de principios del siglo XIX. A Alonso Moreno lo tenemos documentado, al menos, desde 1806, cuando realiza el proyecto frente a la iglesia de San Miguel para el Marqués del Real Tesoro, hasta 1827, en que elabora otro proyecto para el Convento de Santa María del Real de la calle Corcheros (Tetuán) número 35. En mi opinión podríamos fijar la construcción de la casa Andueza en la tercera década del siglo XIX debido a que Vicente Torres de Andueza alcanza en este momento su mejor posicionamiento socio-económico.

El inmueble mantiene el orden y los espacios según las casas tradicionales y. al menos para estos años, es el único ejemplo que tenemos de casa palacio. Su diseño en planta se corresponde con los modelos codificados para estas grandes casas urbanas de fines del siglo XVIII de manera que Azañas La Rua la incluye en su tercer grupo clasificatorio. La obra probablemente se levantó de nueva planta porque, aunque no tenemos referencia documental, la regularidad de sus espacios y líneas así nos lo permiten suponer. Inserta en una manzana rectangular propia del barrio Alonso Moreno trazó en ella una casa de libro pues más o menos en esto consistían los exámenes de limpio que tenían que superar aquellos

${ }^{4}$ A.M.S., Secc. $6^{\mathrm{a}}$, T. 56. En la calle Santa Inés número 30 frente al postigo de la parroquia de San Pedro (así se denominó esta calle en el plano de Olavide hasta que en 1845 pasó a tomar el nombre actual de Doña María Coronel).

${ }^{5}$ Número de registro 005067, realizada en 1958 por Antonio Palau (3-9053).

${ }^{6}$ Comerciante al por mayor. En 1816, 1817 y 1824 fue Cónsul del Consulado Terrestre y Marítimo y en 1818, 1821, 1826 y 1827 Prior del mismo (HEREDIA HERRERA, Antonia: "El Consulado Nuevo de Sevilla y América" en TORRES RAMÍREZ, Bibiano y HERNÁNDEZ PALOMO, José (Coord.): Actas de las V Jornadas de Andalucía y América. Sevilla, 1986, p. 300. 
que querían acceder a la categoría de alarifes o maestros de obras. Sobre un eje de simetría ordenó los espacios en dos crujías de fachada, una a cada lado de un gran patio con columnas para soportar los medios puntos en cuyas galerías dispuso dos escaleras, de señores y de servicio, para comunicar con la planta superior. Otras dos crujías en el frente comunicaban a través de diversas salas con el patio-jardín también rodeado de galerías de columnas sobre arcos que cerraban el fondo del edificio de manera que desde la calle se podía ver, a través de las cancelas, hasta el final de la casa promocionando aquí una trasparencia muy diferente a la que recurre en la casa del Marqués del Real Tesoro en 1806. La cancela, a partir de estos años, sustituye al portón y toma su papel de interrumpir el paso de las personas permitiendo con su trasparencia la visión de los elementos íntimos de la vivienda y la entrada de luz.

En la fachada, de bellas proporciones, los huecos con molduras de orejetas, están dispuestos de forma simétrica respecto a la portada. Ésta destaca por sus dos cuerpos. El primero, con dos pares de columnas de orden toscano apoyadas sobre pódium sujetan un entablamento que soporta el balcón del piso principal. De aquí arranca el segundo cuerpo con otros dos pares de pilastras de orden jónico sobre el que cargan el entablamento superior y un frontón triangular completo decorado con dentellones. Los dos huecos de paso, el del primer piso es de arco segmentado y el de arriba, ligeramente mayor que los vecinos balcones, es adintelado. Una fuerte cornisa separa el conjunto de un antepecho corrido articulado por pedestales que están coronados por jarrones bomboneras mientras que en las esquinas son pináculos piramidales de sabor sevillano. Todos los huecos están enmarcados por unas bandas con dos niveles de profundidad que dan a la fachada, junto con el avance de la portada, una gran articulación y plasticidad. Ésta parece un tipo bastante evolucionado y frecuente en la ciudad. Otras construcciones de este mismo maestro nos pueden servir de ejemplo para ver la persistencia de los modelos pero hay que señalar la escasa obra nueva que se practica por estos años y, sobre todo, destacar la monotonía de estos modelos. Casi todos los maestros hacen parecidos proyectos para pasar el trámite del acto de dación de medidas sin ningún problema para lo cual se ceñían al mismo lenguaje que circulaba entre ellos: huecos alineados horizontal y verticalmente, en el caso de tres alturas, el tercero más pequeño pero guardando la proporción de los demás, en el piso principal la pieza más relevante levemente destacada con un mayor aislamiento, molduras con orejetas en muchas ocasiones, impostas y cornisas apoyadas en ménsulas, huecos adintelados o con arcos segmentados, antepechos corridos apoyados en basamentos o netos coronados por jarrones, vuelos de los balcones según las medidas de las ordenanzas...

El año 1825 marca el antes y el después de esta forma de actuar por parte de los maestros de obra. Es el año en que llega el nuevo Intendente Asistente José Manuel de Arjona que procede de la capital donde había ejercido como regidor en un momento de fuerte transformación de la zona sur de Madrid y, por lo 
tanto, con una gran experiencia en cuestiones urbanísticas. Para promover las reformas que Sevilla necesita y que él detecta rápidamente precisa de un técnico y de inmediato manda llamar a Melchor Cano, arquitecto que ejercía en Madrid y que Arjona conocía seguramente a través de Manuel de la Peña. Melchor Cano, era el único arquitecto en aquellos momentos salido de la Real Academia de San Fernando y, como estaba mandado por diversas Reales Órdenes, podía ejercer el cargo municipal de Arquitecto Mayor. Tenía potestad para actuar en las obras públicas civiles, en las de la Iglesia, Monasterios y Patrimonio Real de tal forma que de inmediato se acumularon en su persona la Maestría Mayor de todas las instituciones civiles y religiosas avaladas por el estatuto académico que había firmado el rey. En él se prohibía que quien no fuese arquitecto por la Real Academia de San Fernando o la de San Carlos de Valencia pudiese dirigir obra en los edificios públicos de cualquier clase.

Poco después de Melchor Cano llegaron a Sevilla otros arquitectos que también habían estudiado en la institución madrileña como Salustiano Ardanaz, José García Otero y Mariano del Río que lógicamente defendieron su supremacía sobre los maestros de obra a la hora de contratar obras de nueva planta lo cual trajo graves problemas por asuntos de competencia. No obstante se observan pocas novedades en los diseños de sus fachadas, únicos documentos que nos permiten hacer un superficial análisis de la arquitectura doméstica ya que lo que se hacía detrás de la fachada no parecía importarle a nadie pues aún no era obligatoria la presentación del plano de planta. Los diseños no podían ser más elementales pues no representaban ni los hierros de cierros y balcones, solo los volúmenes y algunas veces las molduras. Por los pocos interiores que conocemos vemos que el espacio se valora cada vez más y muchas de estas construcciones se renuevan o surgen para la especulación, sobre todo por su dedicación al alquiler.

Melchor Cano va imponiendo sus criterios a los maestro de obras de manera que las fachadas se hacen muy homogéneas y se va consolidando de forma tajante el estilo neoclásico al modo villanovino subrayado también por otros arquitectos que, procedentes de la Real Academia, llegaron a nuestra ciudad en años sucesivos.

A través de los expedientes del Archivo Municipal se puede decir que como características de estos proyectos se impone la desaparición del tejado a dos aguas, tan propio del caserío sevillano. Ahora se sustituye por una terraza amparada por un pretil de obra o de hierros forjados entre netos o pedestales sin jarrones ni otros remates. Las fachadas son limpias, con tres alturas por lo general, con huecos rectangulares bien proporcionados y dispuestos en los ejes principales disminuyendo en altura. Éstos, con mayor frecuencia, eran adintelados aunque también los había de arcos ligeramente rebajados perfilados por molduras simples y coronados por sencillos guardapolvos apoyados sobre ménsulas. Era frecuente que una potente cornisa separara la fachada del pretil y, en algunas ocasiones, se 
destacaba la puerta principal aumentando las proporciones con respecto a los demás huecos (Figura 3).

Como se puede apreciar es un tipo muy frecuente en todas las capitales de provincia por estas fechas debido principalmente a que el control de las ordenanzas sobre ornato público se realiza por aquellos arquitectos salidos de las últimas generaciones de la Real Academia de San Fernando.

Será este el momento de mayor reafirmación del estilo neoclásico en Sevilla con obras interesantes como el Teatro de la calle Muela (San Acasio) del Conde de Guarrazar, el Mercado de la Encarnación, una vez destruido el de maderas levantado por Cayetano Vélez, el frente de Ayuntamiento que da a Plaza Nueva, la propia Plaza Nueva, las Casas del Patrimonio frente a la Torre del Oro (Previsión Española), el teatro de la calle Pasión y el edificio de arcos que cerraba el lado sur de la Plaza de San Francisco una vez derruidos todos los soportales y balconadas que la separaban de la Alcaicería. En fin, salvo el frente del ayuntamiento todos estos edificios han desaparecido en un momento u otro. El lado sur de la plaza obedece a un modelo muy frecuente en aquellas casas que se realizaron para cerrar espacios configurados como y para plazas mayores de muchas ciudades del tipo denominado programadas porque responde a un proyecto único. Este tipo de plazas, en la segunda mitad del siglo XIX, se convierte en el exponente de la prosperidad económica de la ciudad. El edificio se construye entre 1828 y 1833 dentro de la política de adecentamiento del Asistente Arjona. Curiosamente se cierra este lado sur de la plaza de San Francisco con una tipología propia de las plazas mayores muy del estilo que había utilizado Silvestre Pérez a su regreso de Francia en la Plaza Nueva de Bilbao. Este arquitecto, aunque murió en 1825, estuvo en Sevilla en 1824 defendiendo la construcción de un puente fijo de piedra proyectado por él ${ }^{7}$ para el lugar que ocupaba el de barcas y está dentro de lo posible que fuera el autor también de este proyecto para cerrar la plaza que luego terminaría de levantar Melchor Cano dejando como edificios representativos las Casas Capitulares y la Real Audiencia.

El edificio constituiría la parte correspondiente de una hipotética plaza cerrada de soportales con arcos de medio punto sobre pilastras cuadradas existiendo una exacta correspondencia entre el arco de acceso a las viviendas o locales comerciales sobre cuyos montantes se abrían los entresuelos. Por encima de este primer cuerpo iba un balcón corrido por todo el edificio soportado por fuertes ménsulas. A continuación otros dos pisos de viviendas con huecos a la plaza y antepechos de hierro para conservar su función primigenia de mirador o platea para espectáculos. Por último se remataba con una cornisa sobre la que apoyaba un antepecho dividido por pedestales que cerraban un espacio aterrazado al que daban las últimas viviendas retranqueadas para salvar la intimidad y ofrecer

${ }^{7}$ BARCIA, Ángel M. : Catálogo de la colección de dibujos de la Biblioteca Nacional. Madrid, 1906, p. 248, n 1.621. 
un espectacular mirador a la plaza (Figura 4). De haberse construido completamente hubiera contribuido a la existencia de esa plaza mayor que fue característica de muchas ciudades en el siglo XIX.

En los comienzos del reinado de Isabel II ya se han producido acontecimientos importantes para la evolución y el desarrollo de la arquitectura en nuestra ciudad. Por un lado han desaparecido los gremios (1834) y, en particular el de albañilería, víctimas de la nueva apertura a los nuevos sistemas productivos más eficientes. Poco después, en 1836, se lleva a cabo la desamortización de Mendizábal y de nuevo en 1855 la de Madoz.

La desaparición del gremio de albañilería, entre otros, va a permitir a los arquitectos apoderarse del diseño de las obras particulares que antes compartían con los maestros de obras. En Sevilla, por ahora, las tendencias neoclásicas siguen reafirmadas en manos de aquellos arquitectos que siguieron a la venida de Melchor Cano como José Manuel Caballero, Mariano del Río, Salustiano Ardanaz o García Otero. Incluso siguió siendo así con los de la siguiente generación, la de Angel Ayala, Balbino Marrón y José de la Coba.

Las desamortizaciones, aunque es algo que habría que valorar en otro lugar, pusieron a disposición de la incipiente burguesía y de la clase adinerada, como eran todos aquellos que volvían de América con dinero contante, una cantidad de terrenos edificables y de edificios verdaderamente ingentes. A partir de ahora, tras las pertinentes ordenaciones, loteos, subastas, etc. vamos a asistir a la mayor transformación y a la mayor liberación y oferta de terrenos para la construcción de nuevas viviendas a lo largo del siglo XIX.

Así, Balbino Marrón, como Arquitecto Municipal, ante esta situación y con la llegada del ferrocarril en un futuro inmediato, organiza el loteo y subastas en el borde occidental de la ciudad hasta tomar contacto con el río. En 1852 y 1858 ordena las afueras de la Puerta de Triana, espacio que desde la plaza de toros llega hasta la valla del ferrocarril y desde la muralla hasta el río. En 1859 realiza una operación similar en el interior atirantando y loteando los irregulares bordes de la Alameda de Hércules (Figura 5), sobre todo el lado occidental y en el oriental loteando el convento de Belén, fruto de la desamortización. Poco después, con la llegada del ferrocarril, se va organizando el borde de Torneo y se ordena el arrabal de los Humeros donde se crean nuevos solares atirantando líneas y prolongando las calles de Baños, Espejo, Rosal y Caldereros. Unos años más tarde Manuel Galiano completa y termina de definir las parcelas del borde norte desde la Barqueta a la Macarena contemplando también el derribo de la muralla.

Todos estos nuevos espacios surgidos tras las ordenaciones serán los lugares donde las nuevas generaciones de arquitectos y maestro de obras, junto con las ganas de invertir de los indianos levantarán la expansión edilicia de la ciudad en la segunda mitad del siglo XIX.

El paso del régimen absolutista al régimen liberal en el reinado de Isabel II propició la revisión de los reglamentos de determinadas instituciones y de las que 
con mayor intensidad lo hizo fue la Real Academia de Bellas Artes de San Fernando que hasta el momento, y desde su fundación en 1752, ejerció, entre otras, la función de velar por la regulación de los estudios de pintura, escultura, arquitectura y grabado. En el caso de la arquitectura era también la encargada de expedir los títulos de arquitecto y ser mediadora en las cuestiones surgidas en el ejercicio de dicha profesión.

En los años centrales del siglo XIX la cultura francesa y su tecnología forman parte de las costumbres y de los gustos de nuestra ciudad. El propio puente de Triana fue un elemento que los sevillanos aceptaron por su sistema novedoso que ya se había ensayado con éxito en París en el puente del Carrousel. Su autor, M. Polonceau, no modificó ni un tornillo de dicho proyecto, solo lo adaptó a las nuevas dimensiones del Guadalquivir".

De la misma forma la clase alta que se movía por la ciudad lo hacía por los paseos junto al río desde Las Delicias al Paseo del Cristina en carruajes copiados o traídos de allende los Pirineos. Se vivía y se vestía a la moda parisina y se iba al nuevo teatro de San Fernando construido por los ingenieros franceses Bernardet y Roault de Fleuri. Aquí tenían su palco los Duques de Montpensier siempre aclamados por un público expectante. En fin, que los referentes sociales eran las ciudades de París y Londres pasando por el filtro de Madrid.

En la quinta década del siglo XIX, dentro de este clima afrancesado que hemos señalado, se produce un giro importante en los estudios de arquitectura hasta ahora dependientes de la Real Academia de San Fernando. En 1844 se crea la Escuela Superior de Arquitectura por Real Decreto firmado en el reinado de Isabel II con lo que las enseñanzas se independizan de la Academia aunque permanecen vinculadas a ésta a través de un profesorado seleccionado entre los académicos. A partir de entonces la institución rompió su vinculación con el clasicismo. De la Escuela Superior comenzaron a salir nuevas promociones de arquitectos que se dispersaron por todo la nación llevando consigo las ideas aprendidas no solo en la nueva escuela sino en las ciudades europeas a donde viajaban como pensionados una vez terminados los estudios. Por otra parte en este cambio se alteraron todos los planes de enseñanzas y entre las asignaturas que se sumaron a los nuevos planes estaba la Historia del Arte.

De la primera promoción es Joaquín Fernández Ayarragaray, natural de Hernani, Guipuzcoa, que alcanza su título en 1850. Independientemente de otras obras de este arquitecto en Sevilla que señalan con bastante precisión los principios de su formación en las novedades venidas de París, es el autor de la casa que se construye en la Alameda de Hércules número 30 para don Lázaro Fernández de Angulo, Marqués de Esquivel, conocida popularmente como la Casa de las Sirenas. Fue edificada en el solar número 2 del Proyecto de Reforma de La Alameda

8 POLONCEAU, Antoine-Rémi: Notice sur le nouveua système: De ponts en Fonte suivi dans la construction du pont du Carrousel par... A Paris, chez Carillan, 1839. 
que realiza en 1852 y luego mejora en 1858 Balbino Marrón. Aquí pretendió el Marqués de Esquivel fijar su residencia en Sevilla construyendo un palacio urbano en el lugar más abierto de la ciudad aunque en aquellos momentos el más insalubre pero con unas perspectivas de futuro magníficas. Era la única alameda amplia y despejada, transformable en un espacio bucólico, apto para el paseo y exhibición de carruajes de lo más selecto de la sociedad de entonces, refrendado en los planes de Manuel Galiano y Eduardo García Pérez.

El proyecto de la Casa de las Sirenas ${ }^{9}$ es heredero de aquellos palacios urbanos madrileños de la época isabelina de la misma manera que éstos lo eran de los parisinos que por estas fechas el Prefecto Haussman demolía para llevar a cabo su revolucionaria idea de ciudad. Siempre se dijo que este palacete había sido realizado por un arquitecto francés. A simple vista esta afirmación era fácilmente defendible, algo evidente que nadie ponía en duda, pero a la hora de concretar nadie se lo atribuía a Joaquín Fernández. Los ejemplos más próximos son el palacio del Marqués de Portugalete en Madrid, situado en la calle Alcalá construido por el arquitecto francés Adolfo Ombrecht en la década de los 60 y el palacio de Indo, proyecto de 1866, construido en el paseo de la Castellana, uno de los barrios más lujosos del Madrid isabelino, por el portorriqueño Mariano Avenoza para el banquero Miguel Sáinz Indo. Era de dos plantas más una de mansardas, ladrillo rojo, piedra blanca y pizarra gris. Estos palacios tenían jardín en los cuatro lados y pabellones aparte en uno de los frentes para caballerías y guadarnés. No se puede dejar atrás el palacio del Marqués de Salamanca, quizás el primero construido con los elementos propios que luego se van a repetir a lo largo del paseo de Recoletos. Proyectado en 1846 por Narciso Pascual de Colomer, aunque su aspecto es más italiano que francés, forma parte de un tipo que adoptó la burguesía adinerada y la nueva nobleza. El de Uceda, situado en el final del paseo de Recoletos en cuyo solar se halla el actual Centro de Colón, fue realizado por Mariano Avenoza en 1866.

La Casa de las Sirenas (1861) se acomoda con precisión a este esquema de materiales y espacio. Ocupa el centro de la parcela de 2.494 varas cuadradas por lo que queda rodeada de un jardín por las cuatro fachadas que, a su vez, se limitan con una magnífica reja ${ }^{10}$ en tres de sus lados. El frente que da a la Alameda desarrolla dos pabellones para cuadras y guadarnés separados por una espectacular verja de hierro fundido de acceso desde donde una doble rampa para carruajes baja hasta el nivel de la calle. El aspecto del conjunto, con los adornos en barro cocido, es de lo más digno, sin grandes ostentaciones y obviamente con el carácter afrancesado tan de moda en aquellos años en la corte y en Sevi1la. Este carácter se acentúa por una cubierta muy peraltada de pizarra gris con

${ }^{9}$ A.M.S. Secc. Obras Públicas. Abecedario de calles, libro del año 1861.

${ }^{10}$ SUÁREZ GARMENDIA, José Manuel: "La verja de la Fábrica de Tabacos de Sevilla", Laboratorio de Arte 17. Sevilla, 2004, pp. 311-325. 
mansardas y un borde de balaustres de remate. No deja de ser un tipo raro en nuestra ciudad aunque no el único y, a pesar de que tiene un patio en el centro, no se puede considerar como sevillano al ser de proporciones mínimas y sin columnas que soporten galerías. Al exterior presenta cuatro fachadas iguales, con los mismos huecos en cada una y con las mismas guarniciones, todo acoplado al orden corintio (Figura 6).

Joaquín Fernández también tuvo entre manos otro proyecto de parecidas características esta vez a petición del Conde Aguiar para ubicarlo en la Puerta Real en los lotes 28 y 30 adquirido tras las subastas a que dieron lugar las nuevas ordenaciones de Balbino Marrón para las Afueras de la Puerta de Triana ${ }^{11}$. Pero el Ayuntamiento le negó los permisos aduciendo que estos lugares estaban destinados a otro tipo de edificio. En el dibujo que se conserva de este proyecto se aprecia que el arquitecto no se aleja mucho de la idea del palacio de La Alameda siendo lo más característico los altos tejados de pizarra gris con mansardas, la gran tapia perimetral y el aislamiento del edificio (Figura 7).

Otros ejemplos que insisten en la influencia francesa que se percibe en Sevilla, ya en la última década del siglo, son la Casa Rosa o Villa Eugenia y el palacio de Yanduri. La Casa Rosa es un proyecto del maestro de obras José Solares para el Marqués de Angulo. Esto es lo que dice el documento del Archivo Municipal para la solicitud del permiso de obras ${ }^{12}$ pero hay ciertas dudas de que sea Solares el autor. Conocemos otras muchas obras de este maestro que trabajó abundantemente en la segunda mitad del siglo XIX y no tienen nada parecido a la que va a ser Villa Eugenia. Era frecuente que el proyecto lo diseñara un arquitecto y lo presentara firmado un maestro de obras como suyo bien porque las tasas eran más económicas o bien porque el arquitecto era extranjero o residía fuera de la ciudad y no permitían los arquitectos sevillanos esta competencia. El hecho de estar extramuros, en el final del paseo ribereño de la Bella Flor y próxima a la Fuente del Abanico encajaba a la perfección con ese galicismo que la caracteriza y muy próxima a los aspectos vistos en la Casa de las Sirenas (tejados verticales de pizarra, mansardas, carácter aislado, alta cerca, temas decorativos) aunque aquí se emplean nuevos materiales como el hierro y el vidrio.

Joaquín Fernández generaliza también otros proyectos que no son característicos de la ciudad, sobre todo aquellos que se realizan en zonas de ensanche o nueva ordenación como pueden ser los surgidos en la Afueras de Puerta de Triana tras las subastas habidas después de la ordenación del barrio de la Carretería y de lo que fuera el Campo de Marte por Balbino marrón en 1858, así como los

${ }^{11}$ A.M.S., Secc. Obras Públicas, Abecedario de calles, libro del año 1868. Este lote limitaba al oeste por la muralla y comprendía una superficie de 700 metros cuadrados en el que se construyeron posteriormente unas viviendas y un mercado cuyo autor fue José Gómez Otero.

${ }^{12}$ Ibídem, carpeta 1893-94, doc. 38, glorieta del Paraíso (Delicias). 
sobrantes entre la Puerta de Triana y la Puerta Real. Muchos de estos lotes subastados fueron comprados por industriales y prósperos comerciantes con la idea de establecerse, como los Portilla, Grosso, Pickman, Benito Ferrer, Vázquez... y otros más con miras especulativas como Cambio Universal, Oñativia...

Fernández Ayarragaray, en la confluencia de las calles Rábida (Marqués de Paradas) y Albuera, proyectó seis viviendas en los lotes de terreno 20 y 21 adjudicados a Ricardo García. Las viviendas se hicieron con el mayor criterio de modernidad. No tuvo las limitaciones propias del solar aunque no utilizó paralelogramos para diseñar cada vivienda pues se tuvo que adaptar a una superficie trapezoidal (Figura 8). La ventilación interior la resolvió con un patinillo común a las dos viviendas centrales y las demás con patios de luces francamente pequeños. Junto a éstos estaban las escaleras que subían a la planta superior. En el plano de planta se observa la ocupación exhaustiva del espacio que ya se valora de forma más eficiente. Dispone de todas las piezas de una vivienda moderna, se empieza a ver en los diseños de los nuevos arquitectos, salas, alcobas con gabinete y otras con tocador, zaguán, galerías y corredor, comedor, cocina y despensa... Solo los comunes están reducidos a la mínima expresión en comunicación franca con la cocina. El abastecimiento de agua se resolvía con un pozo dispuesto en la cocina y común para cuatro viviendas.

Otros arquitectos de la mitad el siglo que salieron en las primeras promociones de la Escuela de Arquitecturas fueron Eduardo García Pérez, Manuel Galiano, Demetrio de los Ríos y Juan de Talavera y de la Vega. A ellos les tocó vivir un momento de transformación de la ciudad y de una gran demanda de viviendas para hacer frente a las necesidades que planteaba la clase obrera inmigrante del campo que vivía en las peores condiciones de higiene. El conocimiento de esta situación creaba un sentimiento muy extendido entre las clases privilegiadas en las cuales había una creciente preocupación por los asuntos higiénicos y de bienestar que generó que se ensayaran varios tipos de viviendas colectivas derivadas de los inhóspitos corrales que van a progresar poco a poco hacia viviendas individuales y mejor dotadas. No obstante se seguían adaptando edificios en desuso, viejos y nada confortables, como las casas de partido, que se hacían habitables por obra y gracia de la cal cuyo uso obligatorio estaba previsto en las ordenanzas municipales. Se ensayaron todo tipo de fórmulas para proporcionar una accesible forma de pago para estas viviendas de obreros pero todo fue una entelequia y un fracaso.

Eduardo García Pérez fue el arquitecto más vinculado al tema de las mejoras higiénicas. Obtiene el título en la escuela de Madrid en el año 1855 y poco después ya está en Sevilla como profesor de los estudios de maestros de obras y aparejadores. Mantiene una estrecha relación con sus alumnos sobre asuntos de salubridad e higiene en los edificios influido por las corrientes higienistas que tratan de imponerse en las ciudades industriales o en aquellas que en estos momentos están transformándose de forma radical como es el caso del París de Haussman a donde viaja en 1867 para conocer de primera mano la gigantesca 
obra que allí se lleva a cabo. De la misma forma está atento a lo que se hace en Madrid y Barcelona con el Plan Castro y la transformación de Ildefonso Cerdá.

Él participó como académico en la profunda transformación que sufrió la Ronda de Poniente (calle Torneo) con la acometida del ferrocarril hasta la Plaza de Armas configurando su trazado. Como arquitecto en la calle Torneo, núme$\operatorname{ros} 9,10,11,12$ y 13 ejecuta un proyecto de viviendas para varias familias dedicadas al laboreo del carbón, actividad ésta característica del arrabal. Se plantea por tanto una casa de carácter mixto, por un lado como vivienda para las familias ocupadas en la manipulación del carbón y por otro como lugar de almacenaje del mismo. Incluso dentro de los espacios dedicados a viviendas los vemos de dos clases. Una de ellas, en el interior, tenía tipología de corral con una sala cuadrada, puerta y ventana que dan a los corredores sobre el patio rectangular y las cocinas, a veces con dobles anafres. El otro tipo, sobre doble crujía delantera de organización más compleja, con más salas y pasillos, es una vivienda de cierto nivel pero que tenía que compartir con las de tipo corral los servicios y lavaderos.

A Eduardo García Pérez lo que le preocupó en todo momento fueron los aspectos higiénicos más que los tipológicos, lo que dejó muy claro en la memoria del proyecto. En la misma se traslucen los intereses del arquitecto en este sentido describiendo las características técnicas adoptadas a mejorar las condiciones de salubridad como era elevar el piso 30 centímetros para evitar la humedad..., la luz de los patios y patinillos se ha hecho mayor de la sexta parte de la superficie que era lo establecido..., los huecos que dan luz y ventilación a las habitaciones tienen al menos un metro cuadrado de superficie por cada 20 metros de capacidad cúbica..., en las habitaciones que dan al patio interior, provistas todas de una puerta y una ventana se ha colocado un patinillo entre cada dos habitaciones el cual, además de servir para colocar las cocinas es importante para la ventilación al producir una corriente con los huecos ( puerta y ventana) opuestos en el testero de enfrente. Este sistema de corrientes de aire era favorecido también por hallarse aquí el tubo de la chimenea produciendo un tiro favorable con el aire que penetraba en sentido horizontal. Los comunes tendrán un vaso y sifón para hacerlos inodoros al máximo y al comunicar con otros patinillos se construirán aquí los pozos de aguas sucias independizándolas de las aguas llovedizas. La limpieza de las casas y el abastecimiento de aguas potables será mediante pozos y fuentes colocadas en el patio. Las escaleras tendrán $1 \mathrm{~m}, 50$ de ancho con peralte de 0 m, 15 y 0 m, 25 de huella. Los depósitos de carbón para más seguridad serán cubiertos con bóveda de ladrillo. Probablemente será la primera construcción con una memoria facultativa que se ocupe tan intensamente de los aspectos higiénicos ${ }^{13}$.

${ }^{13}$ SUÁREZ GARMENDIA, José Manuel: Arquitectura y Urbanismo... Op. Cit., pp. 114-115. También publicado por DEL POZO Y BARAJAS, Alfonso en Arrabales de Sevilla. Morfogénesis y transformación. El arrabal de los Humeros, Sevilla, 1996, pp. 303-304. 
De este autor vamos a ver otra obra dirigida a una clase social completamente diferente porque es un prototipo de la vivienda que demanda la buena sociedad de entonces. En 1872 doña Amalia Sánchez de Quirós, viuda de Parladé, le encarga su vivienda en la calle Miguel de Mañara (Figura 9). Será suntuosa como corresponde. Podía haber sido un palacete urbano al estilo de los madrileños pero el lugar no da para un solar suficiente que permita un edificio aislado rodeado de unas bandas vegetales y su verja correspondiente. Se tiene que construir entre medianeras pero queda en un extremo un talón libre que se aprovecha como pequeño jardín. Aunque tiene un aspecto afrancesado gozó sin embargo de los elementos más castizos. García Pérez parece que quiere combinar ambas cosas al realizar una fachada con los elementos ordenados como en los palacios madrileños pero sin renunciar a un magnífico patio cuadrado, columnado sobre el que cabalgan arcos de medio punto en el bajo soportando las galerías altas, precedido de un amplio zaguán con cancela de hierro fundido.

La fachada es de una composición muy regular. Los huecos están dispuestos de forma simétrica respecto a un eje con guarniciones elegantes de guardapolvos soportados por ménsulas, realizado todo en ladrillo tallado, y cerrados por hierros fundidos del catálogo de Manuel Grosso. Se interrumpe esta ordenación por un cuerpo central levemente avanzado y limitado por dos cadenetas que llegan hasta el ático en cuyo espacio hay un frontón curvo partido donde se introduce otra ventana también con frontón curvo. Este cuerpo es muy independiente de la composición general de la fachada. En la parte inferior se alberga la portada principal formada por un conjunto de corte dieciochesco pero de trazado más actual con huecos de medio punto, pilastras cajeadas y otras de cadenetas con círculos en las enjutas y una clave en forma de varios dragones. La portada enlaza con el segundo cuerpo a través de una ménsula y presenta el hueco principal que identificamos como la habitación del dueño de la casa. Está guarnecido con un hierro abalconado del mismo diseño que los anteriores. El edificio, como se aprecia en el dibujo del expediente ${ }^{14}$, es una remodelación de una casa del siglo XVIII en la cual se conservan algunos elementos y se sustituyen otros como la ordenación de huecos y, sobre todo, según ya viene siendo normal, se modifican los áticos y también se pierde el tejado a dos aguas aunque persiste en el retranqueo que lo hace invisible desde la calle.

Manuel Galiano fue de los arquitectos que más trabajaron por estos años centrales del siglo. Terminó la carrera en 1841 cuando aún no estaba creada la Escuela Superior y, por lo tanto, fue alumno de las últimas promociones de la Academia con un profesorado aferrado todavía a las ideas clasicistas que él mantuvo durante sus primeros años en Sevilla. Dejó una obra extensa tanto pública como privada. Fue requerido por grandes propietarios y por algunas sociedades

${ }^{14}$ A.M.S., Secc. Obras Públicas. Inventario 3-VIII-1889, doc. 311. Este proyecto fue encargado en 1871 por Andrés Parladé (Inventario 3-VIII-1889, doc. 209). 
crediticias como Cambio Universal. Para esta compañía realizó numerosas viviendas adoptando algunas de las soluciones más interesantes aun tratándose de tipos ya consagrados como el corral de vecinos propiamente dicho que cuando se dispuso regular y adecuadamente jugó un papel decisivo a la hora de rentabilizar los solares. Hay que ver el corral del siglo XIX como un tipo que evoluciona de formas muy antiguas pero que ahora surge como fórmula específica para cubrir las necesidades de dar cobijo a una clase social como es el proletariado, aquí compuesta de artesanos, inmigrantes del campo que ocupan el sector de la producción, obreros de todo tipo, funcionarios... Galiano utiliza esta fórmula en varias zonas de la ciudad de nuevo crecimiento. También para Cambio Universal y para el Conde Luque realiza dos proyectos en las Afueras de Puerta de Triana. En el primer caso construyó unos almacenes para grano y dos pisos de viviendas encima en torno a un enorme patio interior. Más modestas, pero con el mismo sentido y la misma tipología, fue realizando obras en los solares adquiridos por la Compañía, sobre todo en sitios preferentes próximos a la calle Torneo y estación de Córdoba.

Habrá que mencionar como prototipo el corral levantado en el contexto de las reformas del interior de la ciudad realizadas por el arquitecto Balbino Marrón en 1858. Las viviendas encargadas por la Sociedad Cambio Universal para ocupar la manzana de su propiedad en las calles Crédito/ Lumbreras, conocidas posteriormente como el Corral de los Chícharos (Figura 10), se construyeron exclusivamente para el alquiler por lo que se buscó la máxima rentabilidad. El solar era de forma trapezoidal y en el exterior Galiano utiliza una doble crujía perimetral donde se ubican 21 viviendas de escaleras de dos plantas repitiendo el mismo modelo, salvo las que dan a la calle Lumbreras, que son accesorias de doble sala comunicadas con el patio interior. La dotación de estas casas-escalera es muy completa, con todos los servicios incluidos, con total independencia del patio interior. Adosado a la espalda de las anteriores, dando al patio, se establece un tipo que se organiza en corral con 25 salas dobles en cada piso, con puerta y ventana que dan a las galerías del patio. En el extremo más angosto se sitúan los lavaderos y los comunes. Los anafres, al tener tan poco espacio y falta de ventilación en el interior, se ubican fuera, en las galerías. Las casas tipo escalera no participan por tanto de los aspectos sociales del corral y tienen la ventaja de permitir una ocupación exhaustiva del solar. El conjunto es un tipo mixto muy repetido en el resto de la ciudad.

Algunos inversores, para buscar mayor rentabilidad, acudieron a fórmulas ajenas a la tradición de nuestra ciudad pero que ya eran comunes en otras capitales: los pasajes. Navascués lo señala como tema específicamente Isabelino y los define como simples calles cubiertas con objeto de proteger el comercio instalado en ellas haciendo más gratas las visitas a bazares y cafés, protegiendo a los 
clientes del frío y del calor... ${ }^{15}$. Walter Benjamin, en su pequeña obra sobre París, los llama con bastante precisión...invención reciente del lujo industrial y dice que son unos pasillos con techumbre de cristal y revestimientos de mármol que atraviesan inmuebles enteros cuyos propietarios se han unido con vistas a esta especulación ${ }^{16}$. En Sevilla ninguno de los dos matices citados se dieron en los pasajes pues ni propiciaban visitas de tipo comercial ni evidentemente fueron construcciones de lujo sino simplemente una fórmula de drenaje de las grandes manzanas. Aquí el pasaje tiene otro significado más de acuerdo con la etimología de la palabra: paso, tránsito, calle. En unos casos resultaron de la ocupación de los solares de los conventos, en otros fue un intento de resolver problemas de comunicación. El Pasaje Mallol surge tras la subasta de la huerta del convento de Santa Isabel. En 1890 su propietario, Francisco Mallol presenta un proyecto del maestro Salvador Rey y Peraza para abrir una nueva calle, que luego será particular y con la titulación de su propietario, uniendo la calle de Santa Paula y la plaza de Moravia. El Pasaje Vila Andreu, cuyo propietario era Juan Vila, daba salida al barrio de Santa Cruz a través del palacio de Gelves uniendo la calle Jamerdana con Borceguinería (Mateos Gago). El Pasaje Zamora comunicó las calles del interior, San Clemente y Garci Pérez, con el exterior (La Ronda) atravesando la muralla. Únicamente el Pasaje de Aguiar pudo en un momento tener a la vez una función de tránsito, comunicando las calles Gravina y Marqués de Paradas, y también comercial pues en su zona medial se construyó un mercado cuyo proyecto firmó José Gómez Otero y se inauguró en 1882. El Pasaje González Quijano, originado en el solar del convento de Belén, es el de mayor interés entre otras cosas por haber llegado hasta ahora bastante completo además de por haber sido restaurado en los últimos años. El proyecto fue realizado por el maestro de obras Manuel Gallegos Díaz en 1878. Comunica las calles Peris Mencheta y Relator estando cerrado por unas cancelas en sus extremos que dejan convertido el pasaje en una calle particular. El conjunto se organiza a base de casas escaleras en todo el borde construido. Independientemente mantiene también una estructura de corral en torno a un patio triangular con galerías que se comunica con la calle Peris Mencheta. Es, por tanto, una tipología mixta en la que se perciben muchas conexiones con aquel que proyectara Manuel Galiano en 1861 (Corral de los Chícharos). Evidentemente ninguno de estos pasajes se corresponde con el concepto de los de Walter Benjamin o Pedro Navascués.

Con un concepto parecido al de los pasajes, porque también eran de uso particular, surgieron calles de nueva formación como las generadas por la ordenación de la Huerta de los Toribios, junto a la Puerta de la Macarena, a las que

${ }_{15}$ NAVASCUÉS PALACIO, Pedro: Arquitectura y arquitectos madrileños del siglo XIX. Madrid, 1973, p. 136.

${ }^{16}$ BENJAMIN, Walter: París. Madrid, 2013, pp. 50-51. 
Patricio Sáenz, el promotor, rotuló con su nombre y los de su familia: Antonia Sáenz, Aniceto Sáenz y Eustaquio Barrón.

La ciudad poco a poco va creciendo sobre estos grandes solares que eran fruto de la desamortización de conventos, de Bienes de Propios o de resultas de procesos de alineación. Los años centrales del siglo fueron los más fructíferos y los que más aportaron a lo que serán las bases del movimiento ecléctico e historicista que se avecinaba.

Fecha de recepción: 15 de septiembre de 2014

Fecha de aceptación: 28 de noviembre de 2014

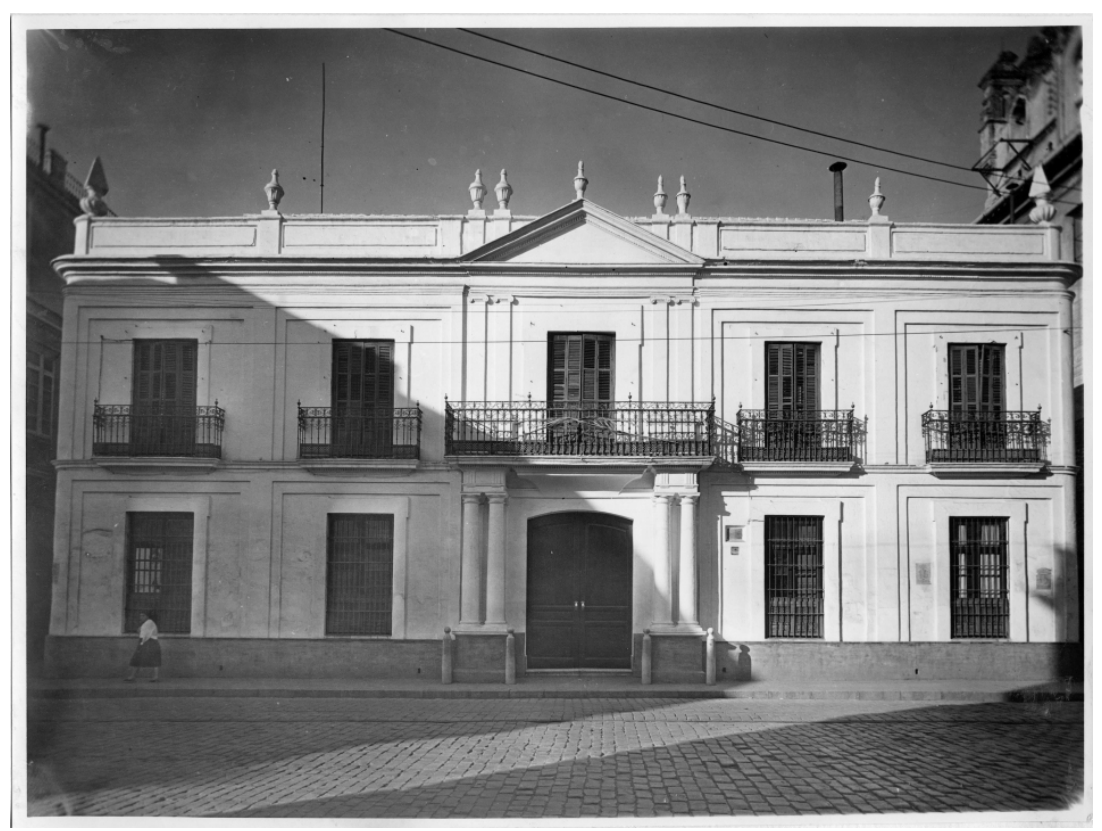

Figura 1. Casa Andueza, Alonso Moreno, circa 1825. 
Figura 2. Calle Doña María Coronel-Alonso Moreno- 1816.

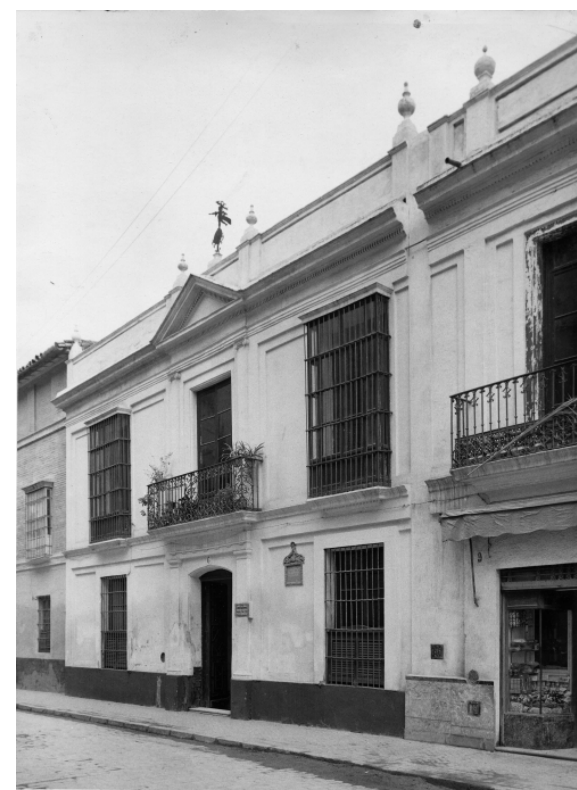

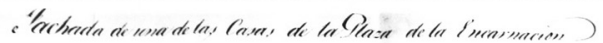

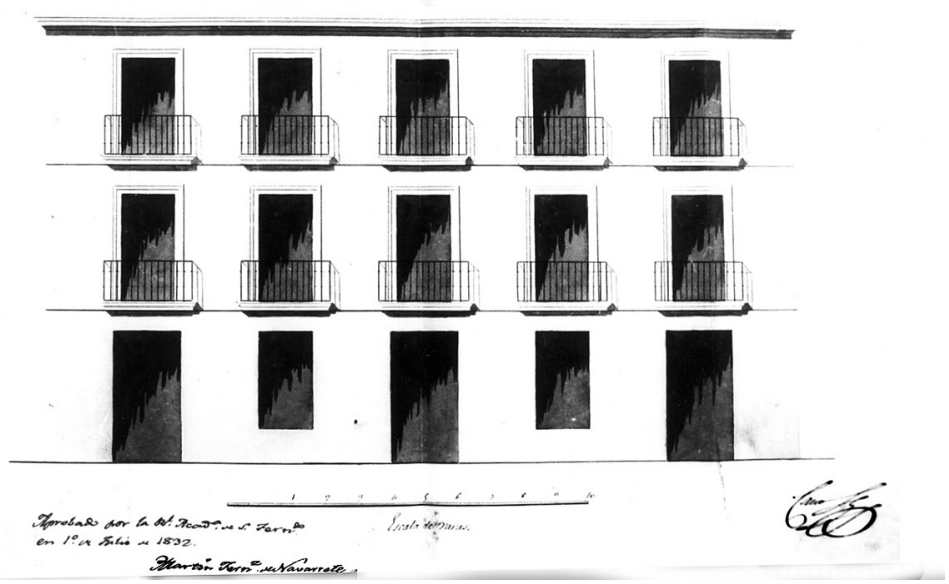

Figura 3. Plaza de la Encarnación, Melchor Cano, 1832. 


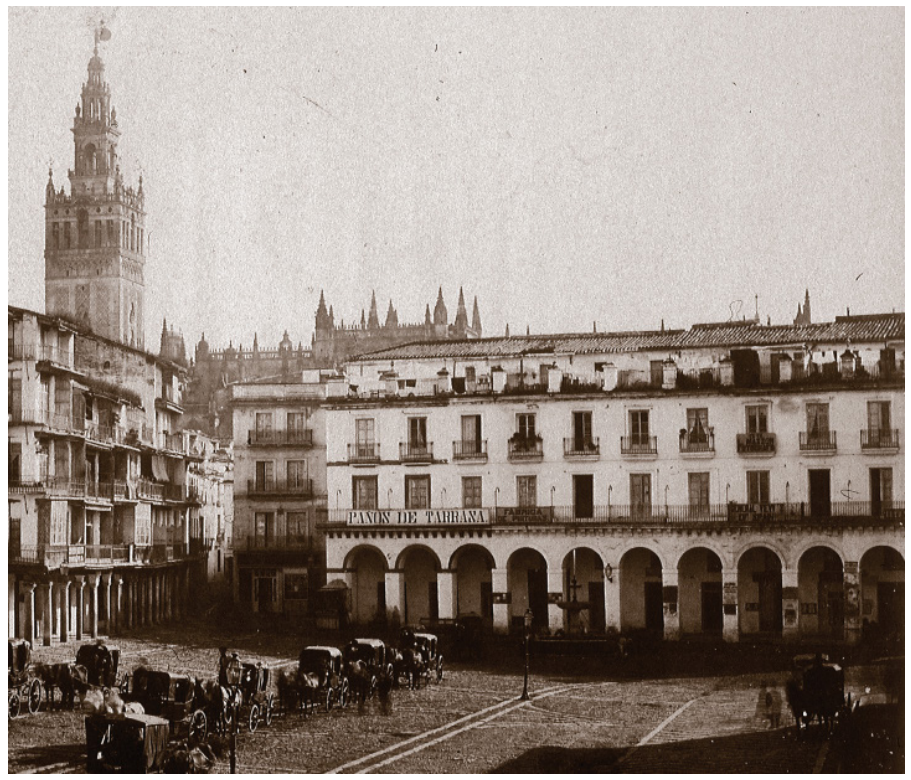

Figura 4. Plaza de San Francisco -Melchor Cano- 1828-1833 (Fot . de J. Laurent).

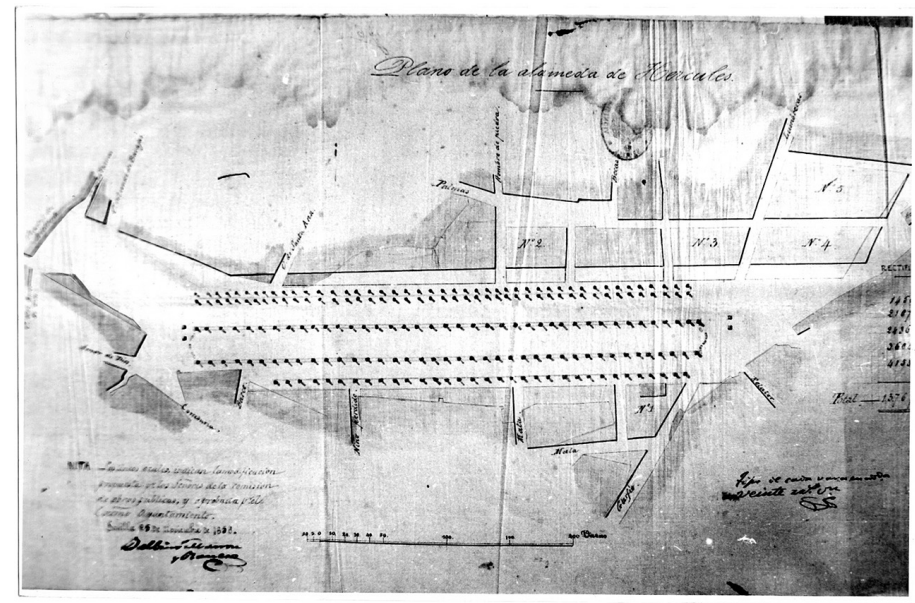

Figura 5. Proyecto de reforma de la Alameda, Balbino Marrón, 1858. 


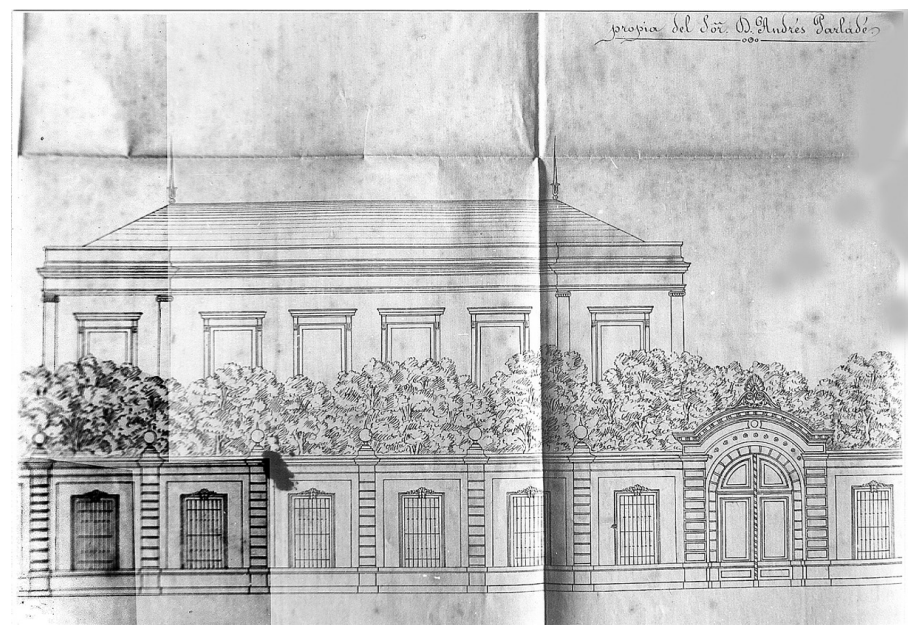

Figura 6. Proyecto para el Conde Aguiar, Joaquín Fernández.

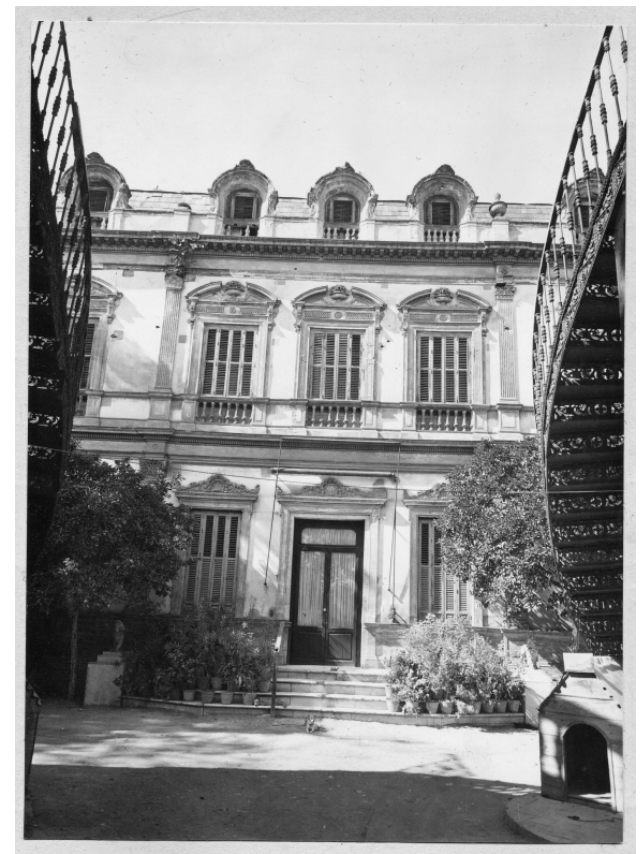

Figura 7. Casa de las Sirenas, Joaquín Fernández, 1861. 


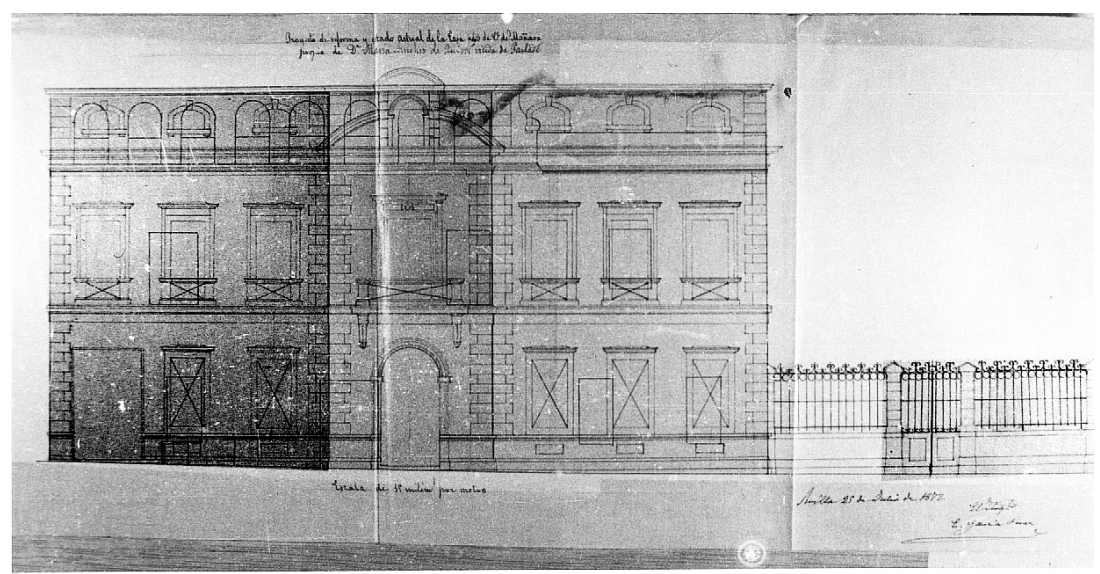

Figura 8. Proyecto para Amalia Sánchez de Quirós en la calle Miguel de Mañara, Eduardo García Pérez, 1872.

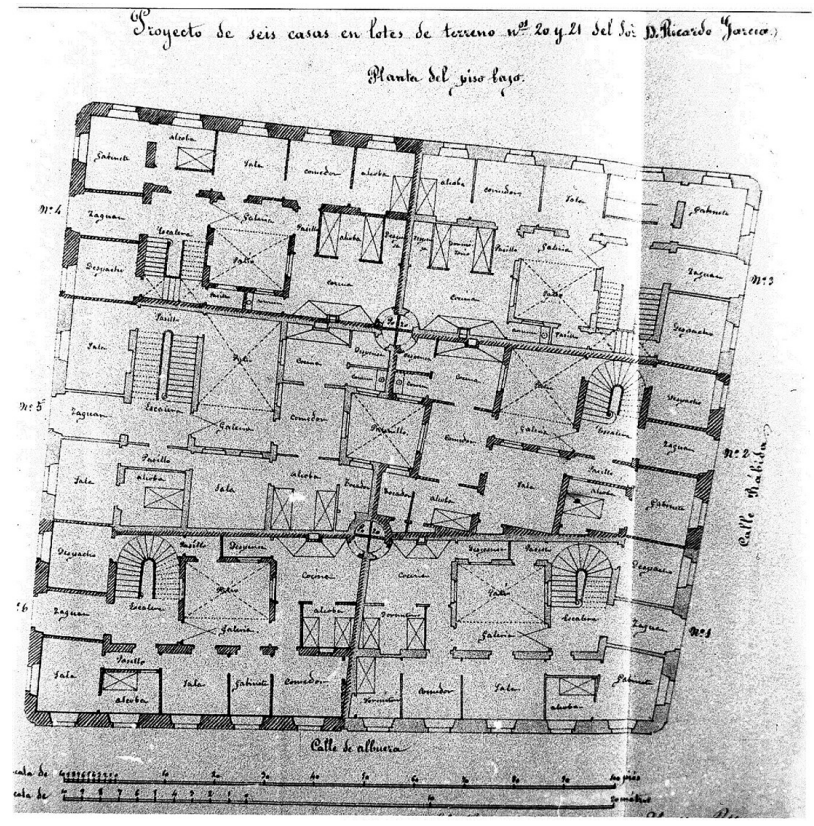

Figura 9. Proyecto para Ricardo García en Marqués de Paradas-Albuera, Joaquín Fernández, 1865. 


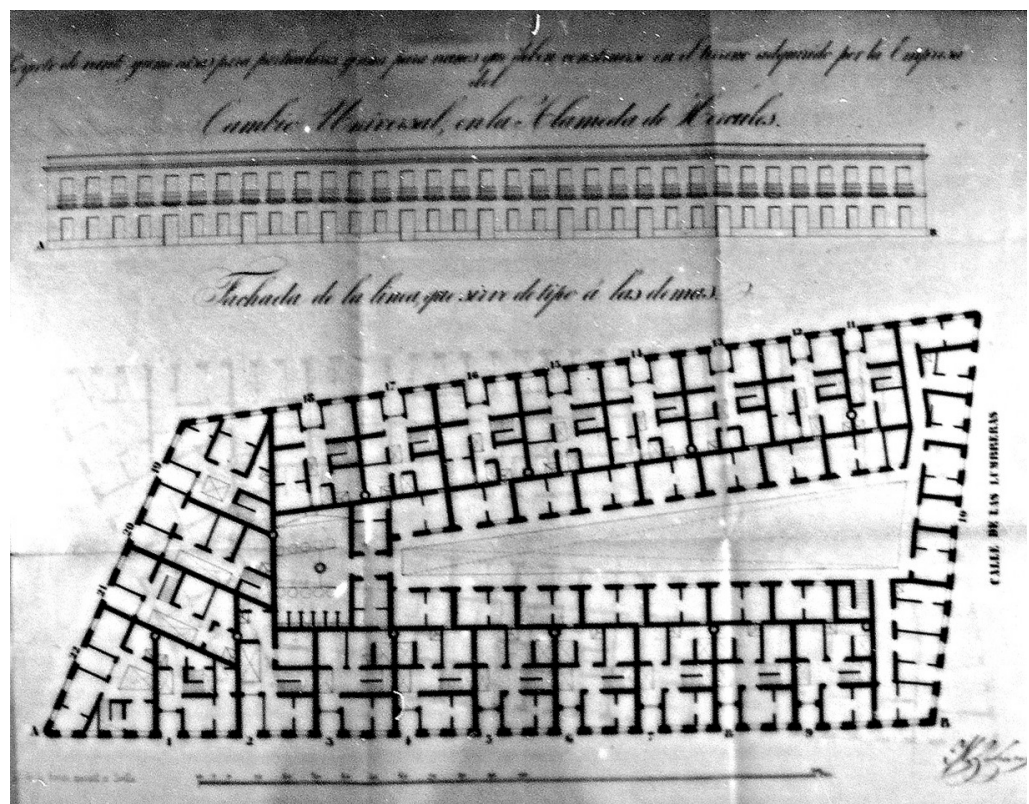

Figura 10. Proyecto para la calle Lumbreras (Corral de los Chícharos), Manuel Galiano, 1861. 